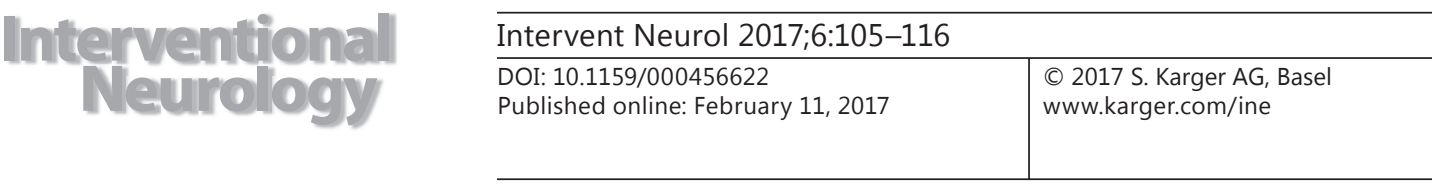

\title{
Radiation Exposure during Neurointerventional Procedures in Modern Biplane Angiographic Systems: A Single-Site Experience
}

\author{
Ameer E. Hassan ${ }^{a}$ Sophie Amelot ${ }^{b}$ \\ aValley Baptist Medical Center, Harlingen, TX, USA; ${ }^{b}$ GE Healthcare, Buc, France
}

\section{Keywords}

Endovascular surgical neuroradiology · Interventional neuroradiology · Radiation exposure

\begin{abstract}
Background and Purpose: Per the ALARA principle, reducing the dose delivered to both patients and staff must be a priority for endovascular therapists, who should monitor their own practice. We evaluated patient exposure to radiation during common neurointerventions performed with a recent flat-panel detector angiographic system and compared our results with those of recently published studies. Methods: All consecutive patients who underwent a diagnostic cerebral angiography or intervention on 2 modern flat-panel detector angiographic biplane systems (Innova IGS 630, GE Healthcare, Chalfont St Giles, UK) from February to November 2015 were retrospectively analyzed. Dose-area product (DAP), cumulative air kerma (CAK) per plane, fluoroscopy time (FT), and total number of digital subtraction angiography (DSA) frames were collected, reported as median (interquartile range), and compared with the previously published literature. Results: A total of 755 consecutive cases were assessed in our institution during the study period, including 398 diagnostic cerebral angiographies and 357 interventions. The DAP (Gy $\left.\times \mathrm{cm}^{2}\right)$, fontal and lateral CAK (Gy), FT (min), and total number of DSA frames were as follows: 43 (33-60), $0.26(0.19-0.33), 0.09(0.07-0.13), 5.6(4.2-7.5)$, and 245 (193-314) for diagnostic cerebral angiographies, and 66 (41-110), $0.46(0.25-0.80), 0.18$ (0.10-0.30), 18.3 (9.1-30.2), and 281 (184-427) for interventions. Conclusion: Our diagnostic cerebral angiography group had a lower median and was in the 75th percentile of DAP and FT when compared with the published literature. For interventions, both DAP and number of DSA frames were significantly lower than the values reported in the literature, despite a higher FT. Subgroup analysis by procedure type also revealed a lower or comparable DAP.
\end{abstract}




\section{Introduction}

Neurointerventional procedures are effective minimally invasive treatment options for various neurovascular conditions (intracranial aneurysm [1, 2], acute ischemic stroke [3, 4], arteriovenous fistula [AVF] or arteriovenous malformation [AVM], etc.). However, because of the complexity of the pathologies to be treated, there is a significant number of procedures requiring prolonged X-ray procedures or high-dose acquisitions, which can result in increased radiation exposure to the patients as well as staff members $[5,6]$, leading to potential deterministic and stochastic adverse effects [7].

The harmful consequences of radiation dose are a rising concern among physicians [8-12] as they face occupational exposure over their lifetime. A recent study showed a correlation between patient dose and occupational dose [13].

As defined by national and international organizations (European Commission Council Directive 97/43/EURATOM [14], International Commission on Radiological Protection [ICRP] [15]), radiation protection is based on 3 fundamental principles: justification, optimization (also known as ALARA), and dose limitation (applicable to occupational and public exposure).

The assessment of patient radiation doses during interventional procedures and their comparison with reference values has been recommended by several professional and regulatory organizations (ICRP, International Atomic Energy Agency [16], and European Commission) as an important component of the optimization process to guide implementation of dose reduction strategies and better control patient radiation exposure. Unfortunately, to date there are only few published radiation data for neurointerventional procedures using modern angiographic systems.

The goal of this study was to establish a baseline of radiation doses at a comprehensive neuroscience center that utilizes contemporary digital equipment for all the different types of neurointerventional procedures and compare them to those in the recently published literature.

\section{Materials and Methods}

This retrospective study was approved by the MetroWest IRB; informed written consent was waived.

All consecutive patients who underwent cerebral diagnostic angiography or endovascular treatment between February and November 2015 in our comprehensive stroke center were retrospectively enrolled. As a reference, our institution activity includes over 1,000 endovascular surgical neuroradiology procedures per year, performed by one of the 2 experienced endovascular neurointerventional radiologists on-site.

Procedures were categorized into 2 groups: cerebral angiography and neurointervention. The neurointervention group was further subdivided into 4 subgroups: (1) embolization of an AVF or AVM, (2) aneurysm embolization, (3) stroke mechanical thrombectomy, and (4) other types of neurointerventional procedures including carotid stenting, intracranial angioplasty and/or stenting, vasospasm treatment, vertebral stenting, microcatheter exploration, and tumor embolizations. All these procedures were performed in one of our 2 angiography biplane rooms (Innova IGS 630, GE Healthcare, Chalfont St Giles, UK) equipped with two $30 \times$ $30 \mathrm{~cm}$ flat-panel detectors with 3-dimensional imaging and advanced imaging capabilities, such as cone beam computed tomography, and 3-dimensional roadmapping. Advanced exposure management allowed dynamic and automatic control of X-ray technique and automatic selection of additional copper filtration. Both systems provide built-in dosimetry indications per exam. Default settings used were fluoroscopy 7.5 fps and multisegment digital subtraction angiography (DSA) with variable framerate $(4,2$, or 1 fps for the different segments). Finally, large display monitors were used and reduced the need for magnification [17].

Both operators use in routine some of the dose reduction strategies described by Pearl and colleagues $[18,19]$, which comprises of the use of fluoroscopy instead of DSA for the femoral access evaluation, the use of a low fluoroscopy framerate $(7.5 \mathrm{fps})$ and variable-framerate DSA, recording of the radiation data, and for follow-up studies the re-use of sequences from previous procedures to minimize the use of DSA for evaluation of the aortic arch. In case of high-flow lesions, a higher DSA framerate is selected. 

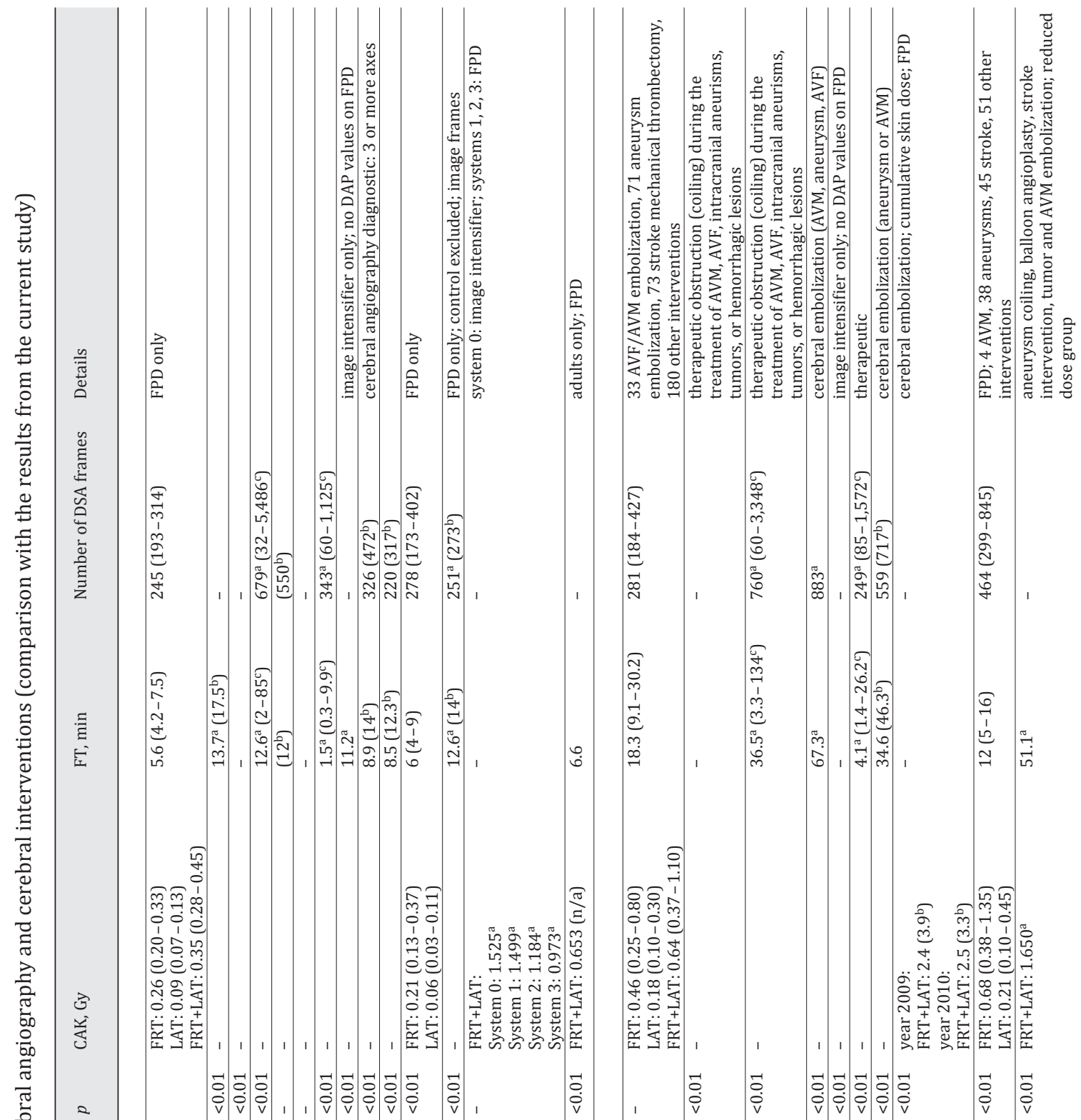

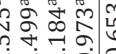

$$
\dot{v} \dot{v} \dot{v} \dot{v}, 1, \dot{v} \dot{v} \dot{v} \dot{v} \dot{v} \dot{v} \vec{v} \quad \dot{v} \quad \dot{v}, 1
$$

定

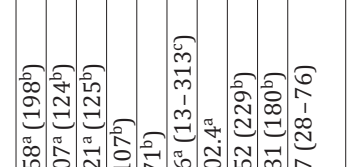

:

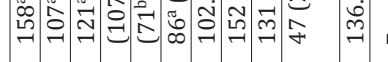

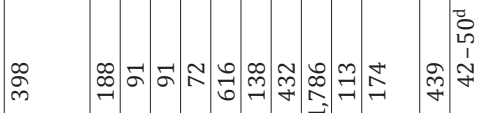

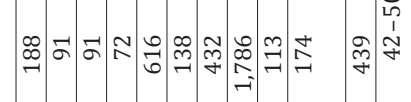

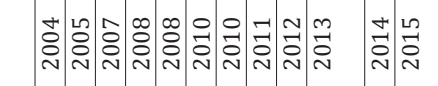

豙乐

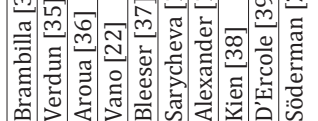

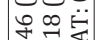

(n)

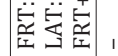

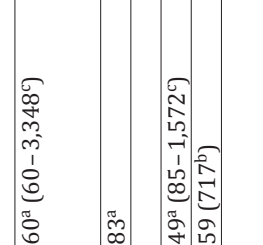

$\sqrt{2}$
0
0
1
2
2
0
0
0
0<smiles>[C]1C=C2C3C=CC(C3)[C@H]12</smiles>

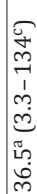

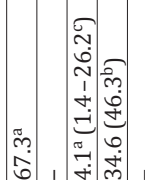

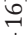

赵

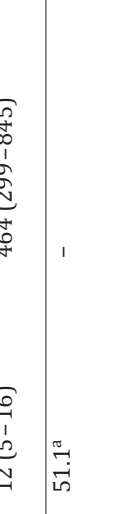




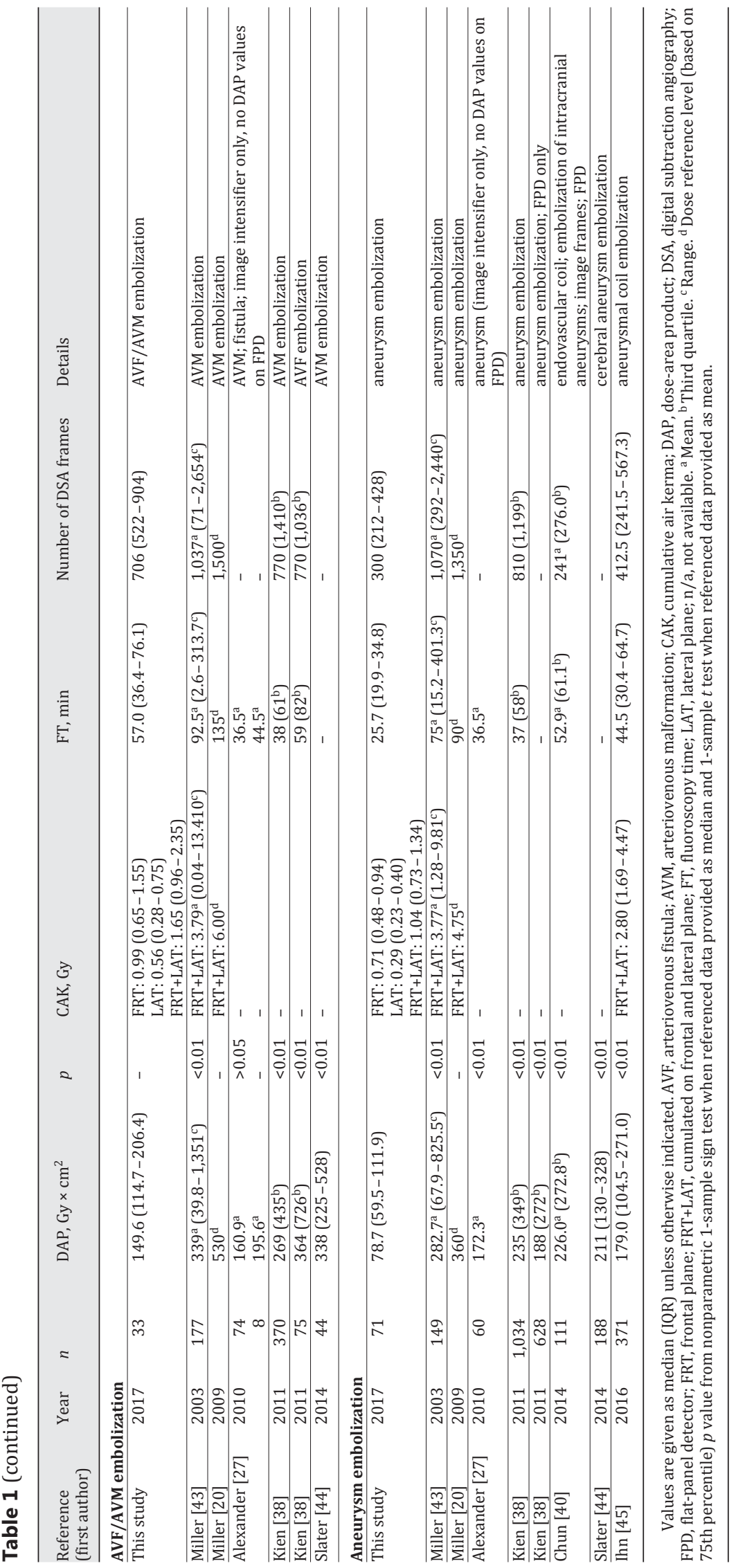


Hassan and Amelot: Radiation Exposure during Neurointerventional Procedures in

Modern Biplane Angiographic Systems: A Single-Site Experience

Table 2. Number of procedures and patient characteristics by type of procedures and split by operator

\begin{tabular}{|c|c|c|c|c|c|c|}
\hline & \multirow{2}{*}{$\begin{array}{l}\text { Number of } \\
\text { procedures }\end{array}$} & \multicolumn{2}{|c|}{ Gender, $n(\%)$} & \multirow{2}{*}{$\begin{array}{l}\text { Age, years, } \\
\text { mean } \pm \text { SD (range) }\end{array}$} & \multicolumn{2}{|c|}{ Operator, $n(\%)$} \\
\hline & & males & females & & 1 & 2 \\
\hline Cerebral angiography & 398 & $213(54)$ & $185(46)$ & $60 \pm 16(8-91)$ & $243(61)$ & $155(39)$ \\
\hline Intervention & 357 & $179(50)$ & $178(50)$ & $60 \pm 16(17-94)$ & $225(63)$ & $132(37)$ \\
\hline AVF/AVM embolization & 33 & $16(48)$ & $17(52)$ & $48 \pm 11(17-65)$ & $23(70)$ & $10(30)$ \\
\hline Aneurysm embolization & 71 & $28(39)$ & $43(61)$ & $58 \pm 14(23-88)$ & $45(63)$ & $26(37)$ \\
\hline Stroke mechanical thrombectomy & 73 & $35(48)$ & $38(52)$ & $73 \pm 12(43-94)$ & $38(52)$ & $35(48)$ \\
\hline Other interventions & 180 & $100(56)$ & $80(44)$ & $58 \pm 17(17-90)$ & $119(66)$ & $61(34)$ \\
\hline Total & 755 & $392(52)$ & $363(48)$ & $60 \pm 16(8-94)$ & $468(62)$ & 287 (38) \\
\hline
\end{tabular}

For each procedure, the following data were collected: patient's demographics (sex, age), procedural details (operator, type of procedure, volume of contrast media, and radiation exposure).

The following indirect dose parameters were provided by the built-in software for both biplane angiographic systems: (1) Summed for both imaging planes (frontal and lateral chain): (a) cumulative dose-area product (DAP, the cumulative air kerma [CAK] multiplied by the exposed area, in $\mathrm{Gy} \times \mathrm{cm}^{2}$ ); (b) CAK, the incident cumulative dose at the interventional reference point (IRP) without backscatter, in mGy; (c) fluoroscopy time (FT) in min; (d) number of DSA frames, with exclusion of number of cone beam computed tomography projections. (2) For each imaging plane: (a) CAK Frontal at IRP in mGy and (b) CAK lateral at IRP in mGy.

In principle, for a relevant comparison of radiation doses, DAP and air kerma should be analyzed based on body size. However, this is not required for cerebral procedures, as there is little variation in size when it comes to head anatomy [20]. Consequently, patients' weight and height were not collected.

In order to compare our radiation dose levels to published reference levels for cerebral diagnostic and interventional procedures, a PubMed search was performed from 2003 on. The radiation data for each procedure are summarized in Table 1. Flat-panel detector technology was also mentioned whenever this information could be retrieved from the publication, as significant reduction in radiation exposure (up to $30 \%$ ) has been reported with this technology in comparison with older-generation image intensifiers [21].

Statistical analysis was done using Microsoft ${ }^{\circledR}$ Excel $^{\circledR} 2010$ (version 14.0.7165.5000) and Minitab ${ }^{\circledR} 17$ statistical software (2010) (version 17.3.1; Minitab Inc.). This was an observational, nonrandomized study; therefore, the statistical analysis was based on descriptive statistical techniques. Categorical variables were presented as numbers and percentages and were compared using the $\chi^{2}$ test. Continuous variables were described with mean, standard deviation, and range, and completed by median and interquartile range for non-normally distributed data as appropriate. The distribution of all continuous variables was assessed with the Shapiro-Wilk test for normality. Correlations were tested by linear and nonparametric Spearman's correlation tests as appropriate. DAP was compared with the literature using the nonparametric 1-sample sign test when referenced data were provided as median and 1-sample $t$ test when referenced data were provided as mean. A 95\% confidence level was used for all statistical calculations and a $p$ value $\leq 0.05$ was considered significant.

\section{Results}

A total of 831 procedures were performed during the inclusion period. When excluding the ones with incomplete datasets, a total of 755 procedures $(91 \%)$ were included in the analysis, with the following procedural split: 53\% cerebral angiography and $47 \%$ neurointerventions. In the interventional group, the repartition in subgroups 1, 2, 3, and 4 was 9, 20, 20, and $50 \%$, respectively.

There was no significant difference in age or gender for cerebral angiography procedures (females $59.1 \pm 17.0$ years vs. males $60.8 \pm 15.5$ years, $p=0.32$ ) and interventional procedures 

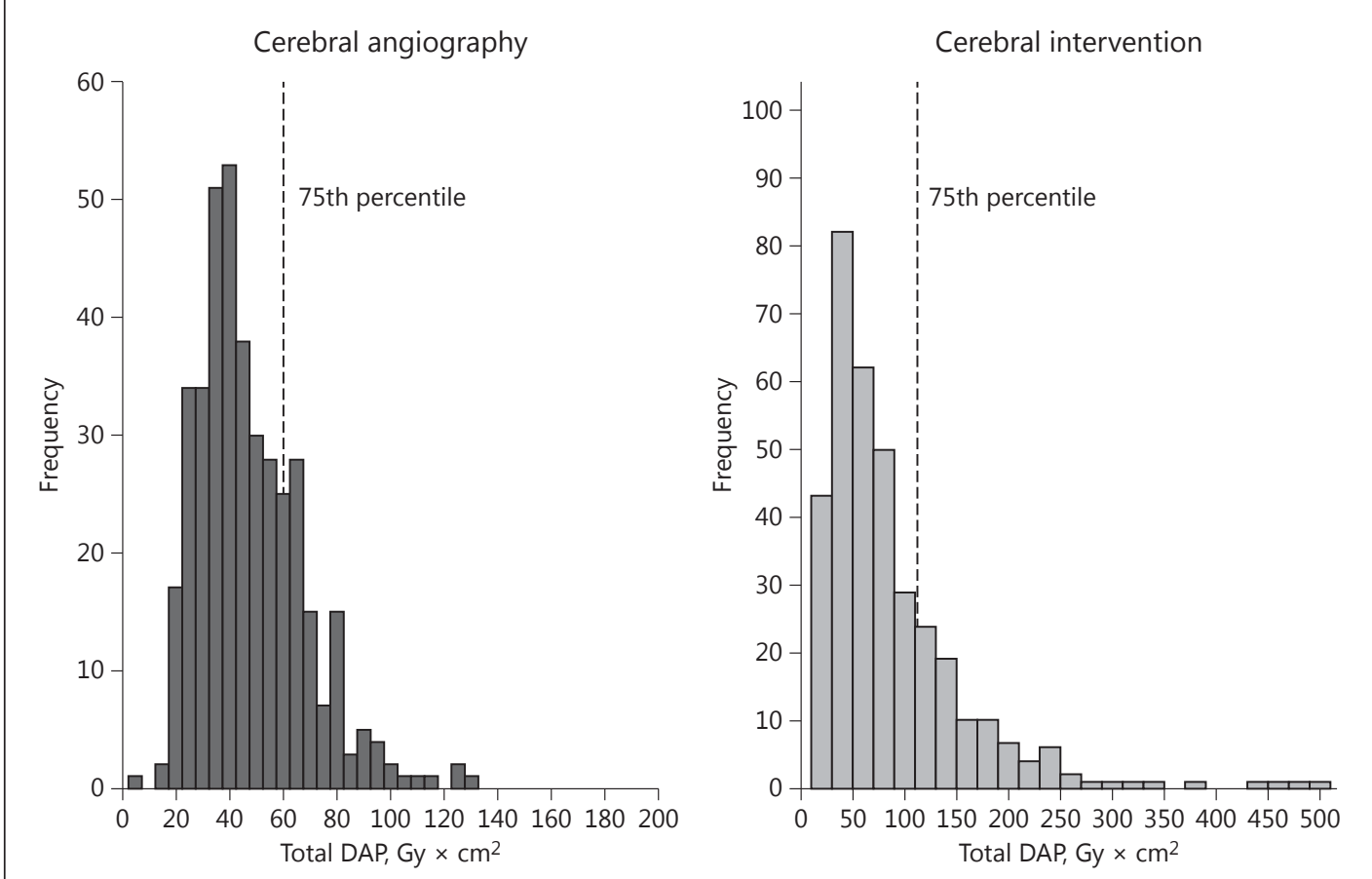

Fig. 1. Distribution of cumulative dose-area product (DAP) $\left(\mathrm{Gy} \times \mathrm{cm}^{2}\right)$ for cerebral angiography and cerebral intervention, with the third quartile represented by the dashed line.

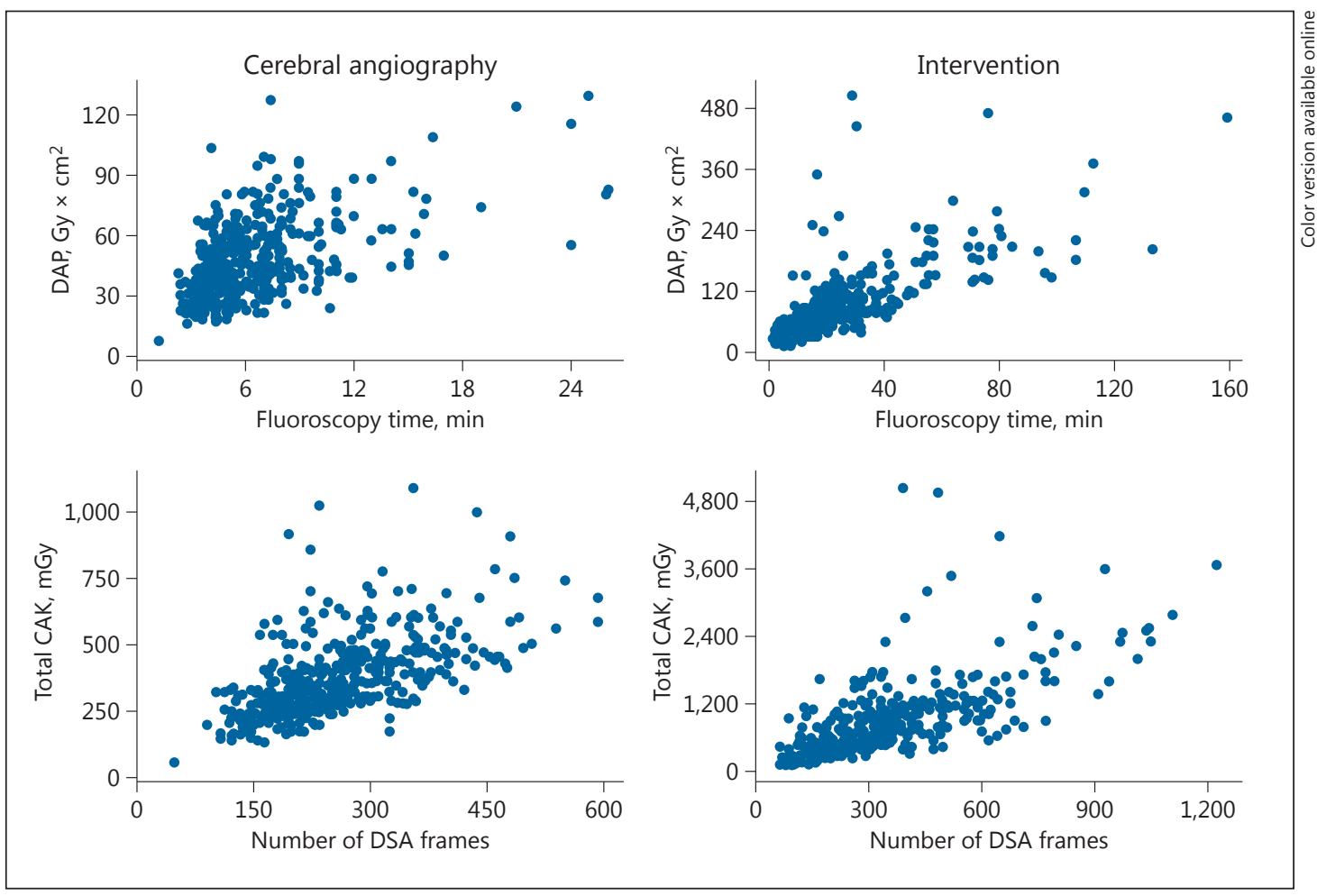

Fig. 2. Scatter plot between dose-area product (DAP)/fluoroscopy time and cumulative air kerma (CAK)/ number of digital subtraction angiography (DSA) frames for cerebral angiography and intervention. 
Hassan and Amelot: Radiation Exposure during Neurointerventional Procedures in

Modern Biplane Angiographic Systems: A Single-Site Experience

Table 3. Radiation dose indicators for diagnostic cerebral angiography and cerebral intervention

\begin{tabular}{|c|c|c|c|c|c|c|}
\hline & \multirow{2}{*}{$\begin{array}{l}\text { Diagnostic } \\
\text { cerebral } \\
\text { angiography }\end{array}$} & \multicolumn{5}{|l|}{ Intervention } \\
\hline & & all interventions & $\begin{array}{l}\text { AVF/AVM } \\
\text { embolization }\end{array}$ & $\begin{array}{l}\text { aneurysm } \\
\text { embolization }\end{array}$ & $\begin{array}{l}\text { stroke mechanical } \\
\text { thrombectomy }\end{array}$ & $\begin{array}{l}\text { other } \\
\text { interventions }\end{array}$ \\
\hline$n$ & 398 & 357 & 33 & 71 & 73 & 180 \\
\hline \multicolumn{7}{|l|}{$\mathrm{DAP}, \mathrm{Gy} \times \mathrm{cm}^{2}$} \\
\hline Mean $\pm S D$ & $47.8 \pm 19.8$ & $88.0 \pm 72.7$ & $163.3 \pm 60.4$ & $97.3 \pm 71.9$ & $90.9 \pm 40.9$ & $69.3 \pm 75.6$ \\
\hline Median (IQR) & $43.1(33.3-59.7)$ & $66.0(40.7-110.8)$ & $149.6(114.7-206.4)$ & $78.7(59.5-111.9)$ & $86.0(59.7-109.9)$ & $43.2(30.4-77.7)$ \\
\hline Range & $7.5-130.1$ & $10.8-505.6$ & $64.6-316.3$ & $25.0-459.9$ & $34.2-240.0$ & $10.8-505.6$ \\
\hline \multicolumn{7}{|l|}{ CAK FRT, mGy } \\
\hline Mean \pm SD & $275 \pm 120$ & $607 \pm 564$ & $1,163 \pm 634$ & $834 \pm 570$ & $575 \pm 296$ & $428 \pm 538$ \\
\hline Median (IQR) & $257(197-330)$ & $460(250-802)$ & $994(654-1,553)$ & $707(479-943)$ & $460(359-757)$ & $267.5(169-529)$ \\
\hline Range & $38-907$ & $67-4,935$ & $403-2,960$ & $272-3,800$ & $189-1,636$ & $67-4,935$ \\
\hline \multicolumn{7}{|l|}{ CAK LAT, mGy } \\
\hline Mean \pm SD & $101 \pm 42$ & $239 \pm 198$ & $546 \pm 241$ & $347 \pm 206$ & $232 \pm 127$ & $143 \pm 116$ \\
\hline Median (IQR) & $93(70-128)$ & $182(102-298)$ & $564(278-746)$ & $288(234-404)$ & $192(147-290)$ & $111(73-172)$ \\
\hline Range & $0-273$ & $0-1,235$ & $225-962$ & $76-1,235$ & $87-673$ & $0-750$ \\
\hline \multicolumn{7}{|l|}{ CAK FRT+LAT, mGy } \\
\hline Mean \pm SD & $376 \pm 149$ & $846 \pm 713$ & $1,709 \pm 835$ & $1,180 \pm 765$ & $807 \pm 397$ & $572 \pm 581$ \\
\hline Median (IQR) & $351(276-450)$ & $639(369-1,104)$ & $1,653(957-2,350)$ & $1,037(727-1,368)$ & $719(503-1,018)$ & $384(252-717)$ \\
\hline Range & $57-1,089$ & $95-5,035$ & $679-3,669$ & $389-5,035$ & $276-2,304$ & $95-4,935$ \\
\hline \multicolumn{7}{|c|}{ Total fluoroscopy time, $0.1 \mathrm{~min}$} \\
\hline Mean \pm SD & $6.5 \pm 3.6$ & $24.4 \pm 22.8$ & $58.2 \pm 26.4$ & $33.9 \pm 27.1$ & $22.7 \pm 12.5$ & $15.0 \pm 14.9$ \\
\hline Median (IQR) & $5.6(4.2-7.5)$ & $18.3(9.1-30.2)$ & $57.0(36.4-76.1)$ & $25.7(19.9-34.8)$ & $19.9(13.1-29.1)$ & $10.1(5.2-20.0)$ \\
\hline Range & $1.2-26$ & $1.8-159.0$ & $18.6-110.0$ & $9.3-159.0$ & $6.5-77.6$ & $1.8-96.2$ \\
\hline \multicolumn{7}{|c|}{ Total number of DSA frames } \\
\hline Mean \pm SD & $259 \pm 92$ & $338 \pm 208$ & $702 \pm 254$ & $330 \pm 154$ & $385 \pm 130$ & $255 \pm 163$ \\
\hline Median (IQR) & $245(193-314)$ & $281(184-427)$ & $706(522-904)$ & $300(212-428)$ & $359(286-458)$ & $206(158-306)$ \\
\hline Range & $48-591$ & $64-1,220$ & $272-1,220$ & $64-743$ & $176-676$ & $64-1,008$ \\
\hline \multicolumn{7}{|c|}{ Volume of contrast media, mL } \\
\hline Mean \pm SD & $55.4 \pm 21.5$ & $74.1 \pm 41.9$ & $95.2 \pm 33.8$ & $90.8 \pm 44.3$ & $89.7 \pm 33.5$ & $57.4 \pm 38.6$ \\
\hline Median (IQR) & $55.0(40.0-70.0)$ & $70.0(40.0-105.0)$ & $100.0(72.5-120.0)$ & $85.0(60.0-110.0)$ & $90.0(63.5-112.5)$ & $45.0(26.5-80.0)$ \\
\hline Range & $6.0-150.0$ & $10.0-200.0$ & $10.0-150.0$ & $20.0-200.0$ & $29.0-160.0$ & $10.0-180.0$ \\
\hline
\end{tabular}

AVF, arteriovenous fistula; AVM, arteriovenous malformation; CAK, cumulative air kerma; DAP, dose-area product; DSA, digital subtraction angiography; FRT, frontal plane; FRT+LAT, cumulated on frontal and lateral plane; IQR, interquartile range; LAT, lateral plane; SD, standard deviation.

(females $59.6 \pm 17.2$ years vs. males $60.7 \pm 15.0$ years, $p=0.53$ ). Except for AVF/AVM embolization, where the sample size is too small, there was no significant difference in gender and age between operators by type of procedure $(p>0.05)$. The population demographics are summarized in Table 2.

The collected radiation dose data were not normally distributed and highly skewed, with an asymmetric shape, as shown in Figure $1(p<0.005)$ representing histograms of DAP for cerebral angiography (398 procedures) and cerebral intervention ( 357 procedures) combined for both operators.

The distribution of DAP, other dosimetry indicators, and the volume of contrast media for diagnostic and therapeutic procedures for both operators are provided in Table 3.

There was a statistically significant difference between the median DAP and CAK among all the procedure types by the Kruskal-Wallis test $(p<0.001)$. Of the analyzed interventional procedures, AVF/AVM embolization had the highest median DAP and CAK $\left(149.6 \mathrm{~Gy} \times \mathrm{cm}^{2}\right.$ and 1,653 mGy, respectively).

Spearman correlations were run to further assess the monotonic relationship between DAP (CAK, respectively) and total FT (number of DSA frames, respectively) for cerebral angiography and neurointerventions (Fig. 2). For cerebral angiography, the correlations were positive, moderate to strong $(0.53<\rho<0.70)$, while for neurointerventions they were positive, strong to very strong $(0.77<\rho<0.881)$. All correlations were statistically significant $(p<$ $0.01)$. 


\section{Discussion}

The main goal of this retrospective and observational study was to characterize the patient-received radiation dose levels during neurointerventional procedures, in a comprehensive center equipped with modern biplane angiographic systems, with representative demographics and procedural mix, and excluding the risk operators' behavior bias towards radiation management.

To provide adequate radiation dose data, due the large individual variability of patient dose in fluoroscopically guided interventional procedures, Vano et al. [22] recommended to collect the radiation data of $>50$ patients within the same type of procedure for a single center. In this study, the number of cases per type of procedures was $>50$ for all categories, except for AVF/AVM.

These results could be used as a reference data point for other centers and help in the assessment of their own practice and the technologies used. Indeed, there is an expected increase in neurovascular programs across the world, due to the recently updated guidelines for the early management of patients with acute ischemic stroke regarding endovascular treatment [23].

Our data showed great variability of dose levels between categories (up to a 3.5-fold difference in the median between the subgroup "other interventions" and "AVF/AVM embolization"), mainly due to the difference in procedure complexity and operator experience.

For cerebral angiography, when comparing the radiation dose with that in the available literature, the DAP median value was found to be significantly lower than the published reference value $(p<0.05)$ (Table 1$)$. Third-quartile DAP and FT were also lower compared to those in the literature. The median FT was found to be significantly lower in 6 out of the 7 references tested for statistical differences. The median number of DSA frames was comparable or lower. Mean CAK was found to be significantly lower in comparison with Chung et al. [24] and Schneider et al. [19].

In the intervention group (Table 1), with all procedures combined, the median DAP was significantly lower than the values reported in literature. FT and number of DSA frames were found to be lower, except in comparison with Sarycheva et al. [25] and Söderman et al. [26]. Sarycheva et al. [25] reported a statistically lower mean of FT and number of frames, using 4 monoplane systems ( 3 equipped with image intensifiers and 1 with a flat-panel detector), but did not provide any precision on the type of therapeutic procedures. The median FT was significantly higher when compared with Söderman et al. [26], which could be explained by a different procedural mix or a larger use of fluoroscopy and stored fluoroscopy in lieu of DSA.

With smaller sample sizes than in other reports of radiation levels, in the subgroups AVF/ AVM embolization and aneurysm embolization, the median DAP was significantly lower $(p<$ 0.01), except for AVM in Alexander et al. [27], for which there was no statistical difference.

As shown in Table 1, the radiation data (DAP and CAK when applicable) from this study were significantly lower than in most of the published literature since 2003, even when compared with modern equipment. No report of dose levels was found in the literature for comparison with our stroke mechanical thrombectomy dose values.

Potential contributors to lower radiation dose, such as low fluoroscopy framerate, use of variable framerate for DSA, digital zoom on a large display monitor, fluorostore, and advanced imaging capabilities could not be investigated due to the retrospective design of the study. Pearl et al. [18] recently made propositions to implement further dose reduction strategies: some of them were already routinely applied at our center as described in the Materials and Methods section, but others, such as the real-time monitoring of radiation parameters with thresholds to better control radiation level during each procedure or the use of a lower default 
DSA framerate (2 vs. 4 fps currently), should also be considered and evaluated with respect to adequate image quality and patient safety.

Optimizing patient radiation is key to reducing scatter radiation and limiting operator dose. However, to further minimize the occupational dose, other protective actions should be considered: personal radiation protection, shielding, operator position, personal dosimeter, and training $[28,29]$.

This comparison also allowed us to reflect the lack of a standardized method to collect and report radiation exposure for neurointerventional procedures. There is a need to develop national reference levels through a multicentric database with standardized radiation data as well as common neurointerventional nomenclature to compare practices as per radiation safety guidelines.

To our knowledge, this study provides the first radiation data related to stroke mechanical thrombectomy. Using the 75th percentile to our results, as commonly done in other studies, for establishing reference levels, preliminary values for this subgroup are $110 \mathrm{~Gy} \times \mathrm{cm}^{2}$ for DAP , 1,020 mGy for CAK, 30 min for FT, and 460 DSA frames. Until broader datasets for stroke mechanical thrombectomy are available, these initial levels could be used by other centers for their own assessment, but should be considered with caution due to the limited sample size and the single-center study design.

Besides the traditional limitation of a single-center retrospective study design, our study has the following additional limitations. In the cerebral diagnostic angiography category, initial diagnostic angiography and follow-up angiographies were not segregated. While initial diagnostic angiography generally refers to the exploration of 4 cerebral vessels or more, follow-up will typically investigate 2 or 3 vessels except in the case of AVF/AVM, which should result in a lower radiation dose.

Per the ALARA principle, there should be a balance between dose and image quality: radiation exposure should not be lowered to a point where the diagnostic level of the images could be jeopardized. In this study, though there was no direct assessment of image quality, the retrospective design suggests that operators focused on procedural success with adequate image quality rather than on achieving low radiation dose alone. The site has been involved in several stroke trials and registries, and their images have to be uploaded and reviewed by national study imaging centers, with no issues having been reported to date. Also, the recanalization rate of mechanical thrombectomy at the site defined as a Thrombolysis in Cerebral Infarction scale score of $2 \mathrm{~b} / 3$ is $88 \%$. It is on par or exceeds the current published data that led to the change in the guidelines for acute stroke treatment - MR CLEAN [4] (59\%), SWIFT PRIME [3] (88\%), ESCAPE [30] (72\%), EXTEND IA [31] (86\%), REVASCAT [32] (66\%), and THERAPY [33] (73\%). Finally, occupational dosimetry data were not available.

\section{Conclusion}

In this study, patient radiation exposure was collected and analyzed for various neurointerventional procedures with varying complexities and found to be in the low range compared to the published literature. According to the ALARA principle, each institution should investigate its own practice regarding radiation exposure and implement dose reduction strategies if required to minimize the dose administered to patients and physicians. In the absence of a safe dose threshold, as technique and equipment continue to evolve, and as the volume and complexity of neurointerventional procedures increase, there would be a need to collect radiation data through local or national surveys to establish reference levels that could help trigger further radiation optimization. 


\section{Disclosure Statement}

Ameer E. Hassan: Financial activities related to the present article: consultant for GE Healthcare. Financial activities not related to the present article: consultant for Medtronic, Microvention, and Styrker. Honorarium from Penumbra. There are no other relationships. Sophie Amelot: Works for GE Healthcare. This research received no specific grant from any funding agency in the public, commercial, or not-for-profit sectors.

\section{References}

1 Molyneux A, Kerr R, Stratton I, Sandercock P, Clarke M, Shrimpton J, Holman R; International Subarachnoid Aneurysm Trial (ISAT) Collaborative Group: International Subarachnoid Aneurysm Trial (ISAT) of neurosurgical clippingversus endovascular coiling in 2143 patients with ruptured intracranial aneurysms: a randomised trial. Lancet 2002;360:1267-1274.

2 Brinjikji W, Rabinstein AA, Lanzino G, Kallmes DF, Cloft HJ: Patient outcomes are better for unruptured cerebral aneurysms treated at centers that preferentially treat with endovascular coiling: a study of the national inpatient sample 2001-2007. AJNR Am J Neuroradiol 2011;32:1065-1070.

3 Saver JL, Goyal M, Bonafe A, Diener HC, Levy EI, Pereira VM, Albers GW, Cognard C, Cohen DJ, Hacke W, Jansen O, Jovin TG, Mattle HP, Nogueira RG, Siddiqui AH, Yavagal DR, Baxter BW, Devlin TG, Lopes DK, Reddy VK, du Mesnil de Rochemont R, Singer OC, Jahan R; SWIFT PRIME Investigators: Stent-retriever thrombectomy after intravenous t-PA vs. t-PA alone in stroke. N Engl J Med 2015;372:2285-2295.

4 Berkhemer OA, Fransen PS, Beumer D, van den Berg LA, Lingsma HF, Yoo AJ, Schonewille WJ, Vos JA, Nederkoorn PJ, Wermer MJ, van Walderveen MA, Staals J, Hofmeijer J, van Oostayen JA, Lycklama à Nijeholt GJ, Boiten J, Brouwer PA, Emmer BJ, de Bruijn SF, van Dijk LC, Kappelle LJ, Lo RH, van Dijk EJ, de Vries J, de Kort PL, van Rooij WJ, van den Berg JS, van Hasselt BA, Aerden LA, Dallinga RJ, Visser MC, Bot JC, Vroomen PC, Eshghi O, Schreuder TH, Heijboer RJ, Keizer K, Tielbeek AV, den Hertog HM, Gerrits DG, van den Berg-Vos RM, Karas GB, Steyerberg EW, Flach HZ, Marquering HA, Sprengers ME, Jenniskens SF, Beenen LF, van den Berg R, Koudstaal PJ, van Zwam WH, Roos YB, van der Lugt A, van Oostenbrugge RJ, Majoie CB, Dippel DW; MR CLEAN Investigators: A randomized trial of intraarterial treatment for acute ischemic stroke. N Engl J Med 2015;372: $11-20$.

5 Vano E, Fernadez JM, Sanchez RM, Martinez D, Lopez Ibor L, Gil A, Serna-Candel C: Patient radiation dose management in the follow-up of potential skin injuries in neuroradiology. AJNR Am J Neuroradiol 2013;34: 277-282.

6 Anastasian ZH, Strozyk D, Meyers PM, Wang S, Berman MF: Radiation exposure of the anesthesiologist in the neurointerventional suite. Anesthesiology 2011;114:512-520.

7 Balter S, Hopewell J, Miller DL, Wagner LK, Zelefsky M: Fluoroscopically guided interventional procedures: a review of radiation effects on patients' skin and hair. Radiology 2010;254:326-341.

8 Roguin A, Goldstein J, Bar 0: Brain tumours among interventional cardiologists: a cause for alarm? Report of four new cases from two cities and a review of the literature. EuroIntervention 2012;7:1081-1086.

9 Roguin A, Goldstein J, Bar O, Goldstein JA: Brain and neck tumors among physicians performing interventional procedures. Am J Cardiol 2013;111:1368-1372.

10 Jackson G: Brain cancer in interventional cardiologists and physicians - is occupational radiation exposure the cause? Int J Clin Pract 2012;66:521.

11 Tavares JB, Sacadura-Leite E, Matoso T, Neto LL, Biscoito L, Campos J, Sousa-Uva A: The importance of protection glasses during neuroangiographies: a study on radiation exposure at the lens of the primary operator. Interv Neuroradiol 2016;22:368-371.

12 Rajaraman P, Doody MM, Yu CL, Preston DL, Miller JS, Sigurdson AJ, Freedman DM, Alexander BH, Little MP, Miller DL, Linet MS: Cancer risks in U.S. radiologic technologists working with fluoroscopically guided interventional procedures, 1994-2008. AJR Am J Roentgenol 2016;206:1101-1108; quiz 1109.

13 Heilmaier C, Kara L, Zuber N, Berthold C, Weishaupt D: Combined use of a patient dose monitoring system and a real-time occupational dose monitoring system for fluoroscopically guided interventions. J Vasc Interv Radiol 2016;27:584-592.

14 Teunen D: The European Directive on health protection of individuals against the dangers of ionising radiation in relation to medical exposures (97/43/EURATOM). J Radiol Prot 1998;18:133-137.

15 The 2007 Recommendations of the International Commission on Radiological Protection. ICRP publication 103. Ann ICRP 2007;37:1-332.

16 International Atomic Energy Agency: Establishing Guidance Levels in X Ray Guided Medical Interventional Procedures: A Pilot Study. Safety Reports Series No. 59. Vienna, IAEA, 2009.

17 Gailloud P: A large display is a powerful tool to reduce radiation exposure during single-plane fluoroscopically guided procedures. AJR Am J Roentgenol 2015;204:W483-W485.

18 Pearl MS, Torok C, Wang J, Wyse E, Mahesh M, Gailloud P: Practical techniques for reducing radiation exposure during cerebral angiography procedures. J Neurointerv Surg 2015;7:141-145. 
19 Schneider T, Wyse E, Pearl MS: Analysis of radiation doses incurred during diagnostic cerebral angiography after the implementation of dose reduction strategies. J Neurointerv Surg 2016, Epub ahead of print.

20 Miller DL, Kwon D, Bonavia GH: Reference levels for patient radiation doses in interventional radiology: proposed initial values for U.S. practice. Radiology 2009;253:753-764.

21 Axelsson B: Optimisation in fluoroscopy. Biomed Imaging Interv J 2007;3:e47.

22 Vano E, Järvinen H, Kosunen A, Bly R, Malone J, Dowling A, Larkin A, Padovani R, Bosmans H, Dragusin O, Jaschke W, Torbica P, Back C, Schreiner A, Bokou C, Kottou S, Tsapaki V, Jankowski J, Papierz S, Domienik J, Werduch A, Nikodemova D, Salat D, Kepler K, Bor MD, Vassileva J, Borisova R, Pellet S, Corbett RH: Patient dose in interventional radiology: a European survey. Radiat Prot Dosimetry 2008;129:39-45.

23 Powers WJ, Derdeyn CP, Biller J, Coffey CS, Hoh BL, Jauch EC, Johnston KC, Johnston SC, Khalessi AA, Kidwell CS, Meschia JF, Ovbiagele B, Yavagal DR; American Heart Association Stroke Council: 2015 American Heart Association/American Stroke Association focused update of the 2013 guidelines for the early management of patients with acute ischemic stroke regarding endovascular treatment: a guideline for healthcare professionals from the American Heart Association/American Stroke Association. Stroke 2015;46:3020-3035.

24 Chung C, Wunderle K, John S, Hui F: Superior radiation dose reduction in modern Siemens bi-plane angiography units. J Neurointerv Surg 2015;7(suppl 1):A80-A81.

25 Sarycheva S, Golikov V, Kalnicky S: Studies of patient doses in interventional radiological examinations. Radiat Prot Dosimetry 2010;139:258-261.

26 Söderman M, Mauti M, Boon S, Omar A, Marteinsdóttir M, Andersson T, Holmin S, Hoornaert B: Radiation dose in neuroangiography using image noise reduction technology: a population study based on 614 patients. Neuroradiology 2013;55:1365-1372.

27 Alexander MD, Oliff MC, Olorunsola OG, Brus-Ramer M, Nickoloff EL, Meyers PM: Patient radiation exposure during diagnostic and therapeutic interventional neuroradiology procedures. J Neurointerv Surg 2010;2:6-10.

28 Vano E, Rosenstein M, Liniecki J, Rehani M, Martin CJ, Vetter RJ: ICRP Publication 113. Education and training in radiological protection for diagnostic and interventional procedures. Ann ICRP 2009;39:7-68.

29 Miller DL, Vañó E, Bartal G, Balter S, Dixon R, Padovani R, Schueler B, Cardella JF, de Baère T; Cardiovascular and Interventional Radiology Society of Europe; Society of Interventional Radiology: Occupational radiation protection in interventional radiology: a joint guideline of the Cardiovascular and Interventional Radiology Society of Europe and the Society of Interventional Radiology. Cardiovasc Intervent Radiol 2010;33:230-239.

30 Goyal M, Demchuk AM, Menon BK, Eesa M, Rempel JL, Thornton J, Roy D, Jovin TG, Willinsky RA, Sapkota BL, Dowlatshahi D, Frei DF, Kamal NR, Montanera WJ, Poppe AY, Ryckborst KJ, Silver FL, Shuaib A, Tampieri D, Williams D, Bang OY, Baxter BW, Burns PA, Choe H, Heo JH, Holmstedt CA, Jankowitz B, Kelly M, Linares G, Mandzia JL, Shankar J, Sohn SI, Swartz RH, Barber PA, Coutts SB, Smith EE, Morrish WF, Weill A, Subramaniam S, Mitha AP, Wong JH, Lowerison MW, Sajobi TT, Hill MD; ESCAPE Trial Investigators: Randomized assessment of rapid endovascular treatment of ischemic stroke. N Engl J Med 2015;372:1019-1030.

31 Campbell BC, Mitchell PJ, Kleinig TJ, Dewey HM, Churilov L, Yassi N, Yan B, Dowling RJ, Parsons MW, Oxley TJ, Wu TY, Brooks M, Simpson MA, Miteff F, Levi CR, Krause M, Harrington TJ, Faulder KC, Steinfort BS, Priglinger M, Ang T, Scroop R, Barber PA, McGuinness B, Wijeratne T, Phan TG, Chong W, Chandra RV, Bladin CF, Badve M, Rice H, de Villiers L, Ma H, Desmond PM, Donnan GA, Davis SM; EXTEND-IA Investigators: Endovascular therapy for ischemic stroke with perfusion-imaging selection. N Engl J Med 2015;372:1009-1018.

32 Jovin TG, Chamorro A, Cobo E, de Miquel MA, Molina CA, Rovira A, Román LS, Serena J, Abilleira S, Ribó M, Millán M, Urra X, Cardona P, López-Cancio E, Tomasello A, Castaño C, Blasco J, Aja L, Dorado L, Quesada H, Rubiera M, Hernandez-Pérez M, Goyal M, Demchuk AM, von Kummer R, Gallofré M, Dávalos A; REVASCAT Trial Investigators: Thrombectomy within 8 hours after symptom onset in ischemic stroke. N Engl J Med 2015;372: 2296-2306.

33 Mocco J, Zaidat 00, von Kummer R, Yoo AJ, Gupta R, Lopes D, Frei D, Shownkeen H, Budzik R, Ajani ZA, Grossman A, Altschul D, McDougall C, Blake L, Fitzsimmons BF, Yavagal D, Terry J, Farkas J, Lee SK, Baxter B, Wiesmann M, Knauth M, Heck D, Hussain S, Chiu D, Alexander MJ, Malisch T, Kirmani J, Miskolczi L, Khatri P; THERAPY Trial Investigators: Aspiration thrombectomy after intravenous alteplase versus intravenous alteplase alone. Stroke 2016;47:2331-2338.

34 Brambilla M, Marano G, Dominietto M, Cotroneo AR, Carriero A: Patient radiation doses and references levels in interventional radiology (in English/Italian). Radiol Med 2004;107:408-418.

35 Verdun FR, Aroua A, Trueb PR, Vock P, Valley JF: Diagnostic and interventional radiology: a strategy to introduce reference dose level taking into account the national practice. Radiat Prot Dosimetry 2005;114: 188-191.

36 Aroua A, Rickli H, Stauffer JC, Schnyder P, Trueb PR, Valley JF, Vock P, Verdun FR: How to set up and apply reference levels in fluoroscopy at a national level. Eur Radiol 2007;17:1621-1633.

37 Bleeser F, Hoornaert MT, Smans K, Struelens L, Buls N, Berus D, Clerinx P, Hambach L, Malchair F, Bosmans H: Diagnostic reference levels in angiography and interventional radiology: a Belgian multi-centre study. Radiat Prot Dosimetry 2008;129:50-55.

38 Kien N, Rehel JL, Étard C, Aubert B: Patient dose during interventional neuroradiology procedures: results from a multi-center study (in French). J Radiol 2011;92:1101-1112.

39 D’Ercole L, Thyrion FZ, Bocchiola M, Mantovani L, Klersy C: Proposed local diagnostic reference levels in angiography and interventional neuroradiology and a preliminary analysis according to the complexity of the procedures. Phys Med 2012;28:61-70. 
Hassan and Amelot: Radiation Exposure during Neurointerventional Procedures in Modern Biplane Angiographic Systems: A Single-Site Experience

40 Chun CW, Kim BS, Lee CH, Ihn YK, Shin YS: Patient radiation dose in diagnostic and interventional procedures for intracranial aneurysms: experience at a single center. Korean J Radiol 2014;15:844-849.

41 Suzuki S, Furui Z, Matsumaru Y, Nobuyuki S, Ebara M, Abe T, Itoh D: Patient skin dose during neuroembolization by multiple-point measurement using a radiosensitive indicator. AJNR Am J Neuroradiol 2008;29: 1076-1081.

42 Kahn EN, Gemmete JJ, Chaudhary N, Thompson BG, Chen K, Christodoulou EG, Pandey AS: Radiation dose reduction during neurointerventional procedures by modification of default settings on biplane angiography equipment. J Neurointerv Surg 2016;8:819-823.

43 Miller DL, Balter S, Cole PE, Lu HT, Berenstein A, Albert R, Schueler BA, Georgia JD, Noonan PT, Russell EJ, Malisch TW, Vogelzang RL, Geisinger M, Cardella JF, George JS, Miller GL 3rd, Anderson J: Radiation doses in interventional radiology procedures: the RAD-IR study: part II: skin dose. J Vasc Interv Radiol 2003;14:977990.

44 Slater L, Hadley C, Soufan C, Yu H, Holt M, Chong W, Maroulis H, Stuckey S, Chandra R: Radiation safety in neurointervention: is it time for dose reference levels? J Neurointerv Surg 2014;6:A6.

45 Ihn YK, Kim BS, Byun JS, Suh SH, Won YD, Lee DH, Kim BM, Kim YS, Jeon P, Ryu CW, Suh SI, Choi DS, Choi SS, Choi JW, Chang HW, Lee JW, Kim SH, Lee YJ, Shin SH, Lim SM, Yoon W, Jeong HW, Han MH: Patient radiation exposure during diagnostic and therapeutic procedures for intracranial aneurysms: a multicenter study. Neurointervention 2016;11:78-85. 